Varetska, O., Nikulochkina O., Tonne O., Kuzminskyi A., Bida O., \& Vdovenko V. (2019). Primary school teacher’s social competence in the postgraduate education. Revista Româneascã pentru Educatie Multidimensionala, 11 (4), 309-327.

MELASH V., SHEVCHENKO Y., VARENYCHENKO A.

Melitopol State Pedagogical University named after Bohdan Khmelnytsky, Ukraine

\title{
INTERCONNECTION BETWEEN THEORY AND PRACTICE BASED ON THE INTRODUCTION OF NEW EDUCATIONAL TECHNOLOGIES AS A PEDAGOGICAL CONDITION OF PROFESSIONAL TRAINING FUTURE PRIMARY SCHOOL TEACHER
}

The analysis of training a future primary school teacher for the formation of environmental culture of primary school children revealed certain drawbacks: in the professional training of students of higher educational establishments, namely to theory and methods of ecological education studying is paid little attention; among the forms of organization of the educational process are dominated traditional ones (lectures and practical classes) of a reproductive nature; the potential of ecology as an integrated science has not been used; the resource of psychological and pedagogical subjects for environmental training of primary school teachers is not fully involved. All this creates a significant gap between the achievements of science and practice of environmental education in the direction of preparing future primary school teachers for the formation of environmental culture of primary school children. The article is devoted to the search for effective pedagogical conditions for training future primary school teachers for the formation of ecological culture of pupils.

The literature on this problem is analyzed, which allows us to conclude that the opinions of scientists are marked by a contradiction about what conditions should be created to ensure the greatest efficiency of the educational process. In general, they determine the pedagogical conditions depending on the direction of their research, in particular: environmental training of future teachers; environmental training of future primary school teachers; formation of the teacher's readiness to intensify the educational process in primary school; development of ecological culture (pupils, future teachers); formation of pupils' caring attitude to nature, a sense of responsibility of pupils. We attach the following meaning to the essence of the concept «pedagogical conditions of preparation of the future primary school teacher for formation of ecological culture of pupils»: it is purposeful and objective possibilities of educational process and the factors and circumstances providing the corresponding process in unity of traditional and innovative approaches. The following pedagogical condition is defined: the organization of the educational process by means of interrelation of theoretical and practical training on the basis of introduction of new educational technologies.

Key words: pedagogical condition, problem learning, ecologically-oriented projects, activity approach to environmental education, training a future primary school teacher, primary school children, formation of environmental culture, natural education.

Стаття надійшла до редакції 08.10.2020 р.

УДК 378.04:[796.012.62:616-082.8

https://doi.org/10.33989/2075-146x.2020.26.227599

\section{СВІТЛАНА МИРОНЕНКО}

ORCID:

ІННА ШАПАРЕНКО

ORCID:

Полтавський національний педагогічний університет імені В.Г. Короленка

\section{ТЕОРЕТИКО-МЕТОДИЧНІ ОСНОВИ ВИКЛАДАННЯ ДИСЦИПЛІНИ «ФІЗИЧНА РЕАБІЛІТАЦІЯ» ПРИ ПІДГОТОВЦІ БАКАЛАВРІВ ЗІ СПЕЦІАЛЬНОСТІ «ФІЗИЧНА КУЛЬТУРА І СПОРТ» У СИСТЕМІ ПРОФЕСІЙНОЇ ПЕДАГОГІЧНОЇ ОСВІТИ}

У статті розкрито теоретико-методичні основи викладання обов'язкової навчальної дисципліни «Фізична реабілітація» в процесі підготовки тренерів освітньо-кваліфікаційного рівня «Бакалавр» на факультеті фізичного виховання Полтавського національного педагогічного університету імені В.Г. Короленка. Визначено мету, завдання вивчення дисципліни, перелік професійних компетентностей та результатів навчання, якими повинні володіти студенти під час вивчення курсу. Наведено та подано детальну характеристику складників навчально-методичного комплексу дисципліни.

Ключові слова: навчально-методичний комплекс, тренер, фізична реабілітація, лікувальна фізична культура, фізичні вправи

Постановка проблеми та її зв'язок із важливими науковими та практичними завданнями. На сучасному етапі дисципліна «Фізична реабілітація» набуває все більшого значення для якісної всебічної підготовки майбутніх 
тренерів. Особливо з питань, що стосуються використання засобів фізичної культури для швидкого відновлення здоров'я, збереження якості життя та профілактики або ліквідації різних видів ускладнень. Комітет експертів ВООЗ визначив, що метою реабілітації є запобігання інвалідності під час лікування захворювань і допомога хворому в досягненні максимальної фізичної, психічної, професійної, соціальної повноцінності (Лисенюк, Ткаліна).

Провідним засобом фізичної реабілітації є лікувальна фізична культура (далі - ЛФК) - застосування фізичних вправ 3 лікувальною й профілактичною метою. ЛФК - найбільш активна, цілеспрямована і дієва складова реабілітаційних і профілактичних заходів, яка не має рівноцінних аналогів за своїм природно-біологічним впливом і тому відіграє головну роль серед засобів не медикаментозного відновного лікування (Вовканич, 2013).

Фізичну реабілітацію слід розглядати як лікувально-педагогічний і виховний процес. Як ми вже з'ясували, основним засобом фізичної реабілітації є фізичні вправи й елементи спорту, а застосування їх - завжди педагогічний, освітній процес. Якість його залежить від того, наскільки тренер оволодів педагогічною майстерністю і знаннями. Тому всі закони й правила загальної педагогіки, а також теорії й методики фізичного виховання надзвичайно важливі в діяльності тренера. Практичним завданням тренера $є$ не тільки сформувати професійні якості тих, хто займається фізичною підготовкою й спортом, але й зберегти й зміцнити здоров'я вихованців. Він зобов'язаний вміти визначати методи й засоби загальної і місцевої дії на організм та диференціювати навантаження в залежності від виду патології і стану здоров'я тих, хто займається фізичною культурою й спортом.

Таким чином, знання з фізичної реабілітації дозволяють тренеру глибоко розуміти суть захворювань та засоби відновлення здоров'я після перенесеної хвороби чи травми й розширюють можливості формування й зміцнення здоров'я вихованців.

Аналіз останніх досліджень і публікацій. Аналіз літературних джерел з проблеми дослідження засвідчив, що теоретико-методологічні аспекти фізичної реабілітації були частково висвітлені в роботах низки науковців: Юмашева Г., Ренке К, Амосова М., Вендета Я., Дзяка В., Карепова Г., Пелеха Л., Клапчука В., Правосудова В., Єпіфанова В., Попова С., Мухіна В., Магльованого А. та ін. Проте питання щодо розробки навчально-методичного забезпечення та особливостей викладання цієї дисципліни при підготовці тренерів в педагогічних ЗВО залишається не достатньо висвітленим.

Це і визначило мету дослідження - розкрити теоретико-методичні основи викладання навчальної дисципліни «Фізична реабілітація» в системі підготовки бакалаврів факультету фізичного виховання Полтавського національного педагогічного університету імені В.Г. Короленка зі спеціальності 017 «Фізична культура і спорт».

Виклад основного матеріалу дослідження. Для забезпечення фундаментальної теоретичної та практичної підготовки висококваліфікованих кадрів, формування їх професійних компетентностей нами розроблено навчальнометодичний комплекс дисципліни, який має такі структурні елементи:

1. Програма навчальної дисципліни.

2. Робоча програма навчальної дисципліни.

3. Опорні конспекти лекцій з питаннями для самоконтролю.

4. Методичні рекомендації до проведення практичних занять.

5. Методичні рекомендації до виконання самостійної роботи.

6. Тестові завдання для поточного контролю знань студентів.

7. Тестові завдання для модульного контролю знань студентів.

8. Тестові завдання для семестрового контролю знань студентів.

9. Критерії оцінювання навчальних досягнень студентів.

10. Пакет комплексних контрольних робіт.

Програма дисципліни «Фізична реабілітація»є авторською (Мироненко, 2018), укладена відповідно до освітньопрофесійної програми підготовки бакалавра зі спеціальності 017 «Фізична культура і спорт», затверджена кафедрою медико-біологічних дисциплін та фізичного виховання і вченою радою факультету фізичного виховання Полтавського національного педагогічного університету імені В.Г. Короленка.

Згідно з вимогами освітньо-професійної програми студенти повинні набути таких компетентностей:

- загальних:

1. Здатності діяти етично, соціально відповідально та свідомо.

2.3датності працювати в команді та автономно.

3.3датності до пошуку інформації, ï аналізу та критичного оцінювання.

4.Здатності застосовувати набуті знання в практичних ситуаціях.

5.Здатності використовувати інформаційно-комунікаційні технології.

6. Здатності до самовдосконалення та саморозвитку.

- фахових:

1. Здатності забезпечувати формування фізичної культури особистості.

2. Здатності визначати заходи з фізкультурно-спортивної реабілітації та форми адаптивного спорту для осіб, що їх потребують.

3. Здатності зміцнювати здоров'я людини шляхом використання рухової активності, раціонального харчування та інших чинників здорового способу життя.

4. Здатності застосовувати знання про будову та функціонування організму людини.

5. Здатності надавати долікарську допомогу під час виникнення невідкладних станів.

6. Здатності аналізувати прояви психіки людини під час занять фізичною культурою і спортом.

7. Здатності використовувати спортивні споруди, спеціальне обладнання та інвентар.

8. Здатності до безперервного професійного розвитку. 
У результаті вивчення дисципліни студенти повинні:

1. Здійснювати аналіз суспільних процесів у сфері фізичної культури і спорту, демонструвати власне бачення шляхів розв'язання існуючих проблем.

2. Показувати навички самостійної роботи, демонструвати критичне та самокритичне мислення.

3. Засвоювати нову фахову інформацію, оцінювати й представляти власний досвід, аналізувати й застосовувати досвід колег.

4. Обгрунтовувати вибір заходів з фізкультурно-спортивної реабілітації та адаптивного спорту.

5. Використовувати засвоєні уміння і навички занять популярними видами рухової активності оздоровчої спрямованості.

6. Застосовувати у професійній діяльності знання анатомічних, фізіологічних, біохімічних, біомеханічних та гігієнічних аспектів занять фізичною культурою і спортом.

7. Визначати функціональний стан організму людини та обгрунтовувати вибір засобів профілактики перенапруження систем організму осіб, які займаються фізичною культурою і спортом.

8. Надавати долікарську медичну допомогу при невідкладних станах та патологічних процесах в організмі людини.

9. Використовувати нормативні та правові акти, що регламентують професійну діяльність.

10. Застосовувати набуті теоретичні знання для розв'язання практичних завдань та змістовно інтерпретувати отримані результати.

Курс «Фізична реабілітація» є обов'язковою дисципліною. На іï вивчення відводиться 120 годин / 4 кредити ЕСТS. Підсумковий контроль передбачає складання студентами екзамену.

Структуру навчальної дисципліни з переліком тем і розподілом годин наведено в табл.1.

Таблиця 1

Структура навчальної дисципліни

\begin{tabular}{|c|c|c|c|c|c|c|c|c|}
\hline \multirow[b]{3}{*}{ Назви тем } & \multicolumn{8}{|c|}{ Кількість годин } \\
\hline & \multicolumn{4}{|c|}{ Денна форма навчання } & \multicolumn{4}{|c|}{ Заочна форма навчання } \\
\hline & : & 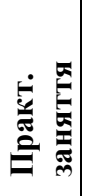 & 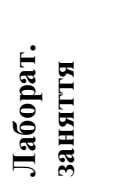 & 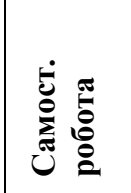 & 春 & 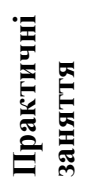 & 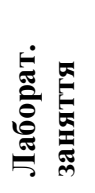 & 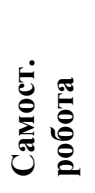 \\
\hline \multicolumn{9}{|c|}{ Змістовий модуль № 1. Фізична реабілітація при внутрішніх хворобах } \\
\hline $\begin{array}{l}\text { Тема 1. Організаційно-методичні } \\
\text { основи фізичної реабілітації }\end{array}$ & 2 & & 2 & 2 & 2 & 2 & & 9 \\
\hline $\begin{array}{l}\text { Тема 2. Фізична реабілітація при } \\
\text { захворюваннях серцево-судинної } \\
\text { системи }\end{array}$ & 2 & & 4 & 6 & 1 & 1 & & 10 \\
\hline $\begin{array}{c}\text { Тема 3. Фізична реабілітація при } \\
\text { захворюваннях обміну речовин }\end{array}$ & 2 & & 2 & 6 & & & & 10 \\
\hline $\begin{array}{c}\text { Тема 4. Фізична реабілітація при } \\
\text { захворюваннях органів дихання }\end{array}$ & 2 & & 2 & 6 & & & & 10 \\
\hline Разом за модуль & 8 & & 10 & 20 & 3 & 3 & & 39 \\
\hline \multicolumn{9}{|c|}{ Змістовий модуль № 2. Фізична реабілітація при травмах і захворюваннях опорно-рухового апарату } \\
\hline $\begin{array}{l}\text { Тема 1. Фізична реабілітація при } \\
\text { дефектах постави та захворюваннях } \\
\text { опорно-рухового апарату }\end{array}$ & 2 & & 4 & 4 & 1 & 1 & & 10 \\
\hline $\begin{array}{l}\text { Тема 2. Фізична реабілітація при } \\
\text { дегенеративних змінах опорно- } \\
\text { рухового апарату. Остеохондроз }\end{array}$ & 2 & & 2 & 10 & 1 & 1 & & 10 \\
\hline $\begin{array}{c}\text { Тема 3. Фізична реабілітація при } \\
\text { захворюваннях та травмах суглобів }\end{array}$ & 2 & & 2 & 10 & 1 & 1 & & 10 \\
\hline $\begin{array}{r}\text { Тема 4. Фізична реабілітація при } \\
\text { переломах довгих трубчастих кісток }\end{array}$ & 2 & & 2 & 10 & & & & 9 \\
\hline Разом за модуль & 8 & & 10 & 34 & 3 & 3 & & 39 \\
\hline $\begin{array}{l}\text { Підготовка до екзамену (якщо } \\
\text { передбачено навч. планом) }\end{array}$ & & & & 30 & & & & 30 \\
\hline Усього годин & 16 & & 20 & 84 & 6 & 6 & & 108 \\
\hline
\end{tabular}


Обгрунтовуючи основні методичні аспекти викладання дисципліни «Фізична реабілітація», наводимо специфічні особливості різних форм аудиторної (лекційні та практичні заняття) та самостійної роботи студентів, а також організаційні засади здійснення усіх видів контролю.

Провідну роль у навчальному процесі вищої школи займає лекція (Отваренко, 2018). Для активізації навчальнопізнавальної діяльності студентів нами використовуються інформаційні лекції, лекції-діалоги та лекції-візуалізації із мультимедійними презентаціями із зазначених вище тем. Слід підкреслити, що у нових реаліях дистанційного навчання надважливого значення набуває візуалізація лекційного матеріалу. Для оптимальної візуалізації теоретичного матеріалу ми використовуємо наступні мультимедійні компоненти: відео, анімацію, фото, схеми, таблиці. Зазначимо, що процес розробки мультимедійної лекції кропіткий, із значними затратами часу, оскільки вимагає від викладача ретельного підбору змісту, ілюстративного матеріалу та його структурування. Проте, згідно наших спостережень, представлення інформації з використанням аудіовізуальних засобів $є$ найбільш ефективною формою навчання.

Важливим компонентом навчально-виховного процесу у ЗВО є практичні роботи. Практичні заняття 3 курсу «Фізична реабілітація» сприяють організації самостійної роботи, дають можливість інтегрувати теоретичні знання із практичними уміннями і навичками, активізувати пізнавальну діяльність студентів. Для забезпечення ефективного засвоєння навчального матеріалу, його поглиблення, закріплення, конкретизації знань та 3 метою практичного підтвердження теоретичних положень даної навчальної дисципліни нами розроблено методичні вказівки до виконання практичних робіт.

Методика проведення практичних занять із дисципліни охоплює декілька етапів:

I. Попередня підготовка полягає в актуалізації теоретичних знань студентів, яка проводиться у формі вирішення тестових завдань та фронтального опитування.

II. Інструктаж щодо методики виконання завдань.

III. Виконання практичної роботи.

IV.Узагальнення отриманих результатів, формулювання висновків та оформлення індивідуального звіту.

Що стосується організаційно-методичних засад проведення практичних робіт, то нами застосовуються фронтальні, групові та індивідуальні форми. Поряд з фронтальною формою організації занять (коли студенти виконують однотипні завдання), широко застосовуємо індивідуальну форму організації практичного заняття, де студенти працюють за розробленими нами картками 3 індивідуальними ситуаційними задачами. У цих завданнях акцентуємо увагу на опануванні майбутніми тренерами методик застосування лікувальної фізичної культури та інших засобів реабілітації в залежності від стану здоров'я тих, хто займається фізичною підготовкою і спортом, наявних захворювань, а також робимо акцент на призначенні інтенсивності занять в кожному окремому випадку. Алгоритм записів практичної роботи є таким: тема і мета заняття, обладнання та інструментарій, хід роботи з детальним описом методики виконання завдань та висновки.

Характерною особливістю навчання у сучасній вищій школі є великий обсяг самостійної роботи студентів, яка $є$ дуже важливою і необхідною складовою частиною їх професійної підготовки. Працюючи самостійно (за консультативної допомоги викладача), студенти закріплюють знання, набувають навичок самоорганізації, самоконтролю, розвивають пізнавальні інтереси та здібності. При вивченні дисципліни «Фізична реабілітація» на цей вид діяльності відведено 2/3 (84 години) усього навчального часу.

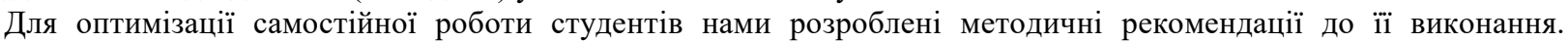
Самостійна робота передбачає: опрацювання додаткових питань із тем, підбір та опрацювання спеціальної літератури, написання рефератів та реферативних повідомлень, робота в мережі Internet. Важливим складником цього виду роботи є створення презентації на тему: «Методика застосування засобів фізичної реабілітації при різних захворюваннях». Для успішного вирішення такого завдання студентам запропоновано наступний алгоритм його виконання:

1. Діагноз і основні клінічні, функціональні дані.

2. ікувальний період для призначення засобів фізичної реабілітації.

3. Показання та протипоказання для призначення засобів фізичної реабілітації.

4. Клініко-фізіологічне обгрунтування призначення фізичної реабілітації (на підставі фізіологічних механізмів лікувальної дії фізичних вправ):

4.1. Спеціальні завдання;

4.2. Загальні завдання.

5. Засоби фізичної реабілітації:

5.1. Руховий режим;

5.2. Фізичні вправи;

5.3. Засоби загартування (вказати, які саме)

6. Форми призначення фізичних вправ:

6.1. Лікувальна гімнастика;

6.2. Самостійні заняття за індивідуальними завданнями;

6.3. Масаж;

6.4. Дозована ходьба;

6.5. Теренкур;

6.6. Працетерапія;

6.7. Механотерапія та заняття на тренажерах;

6.8. Дозоване плавання, гімнастика у воді, душі.

7. Методи проведення занять фізичними вправами.

8. Дозування фізичного навантаження за інтенсивністю (навантаження, що активізує до $50 \%$ 
хронотропного резерву - малої інтенсивності, 51 - 75\% - середньої інтенсивності, понад 75\% - високої інтенсивності).

9. Дозування фізичного навантаження за обсягом і кратністю (на день і на тиждень).

10. Особливості застосування фізичних вправ (навести приклади 10 спеціальних вправ при вибраному захворюванні).

11. Методи і критерії визначення адекватності і ефективності кумулятивної дії засобів фізичної реабілітації.

12. Висновки.

Самостійна робота виконується індивідуально й оформляється у вигляді звіту, який студенти повинні здати викладачу для перевірки не пізніше як за два тижні до останнього заняття.

Оцінювання навчальних досягнень студентів здійснюється нами за всіма видами робіт (аудиторної та самостійної) і передбачає такі форми педагогічного контролю: поточний, модульний та підсумковий.

Поточний контроль знань студентів нами проводиться у формі фронтального й бліц-опитування та вирішення тестових завдань. Проте, в більшості випадків використовуємо тестову методику 3 альтернативним вибором відповідей. Перевага цієї форми обумовлена об’ єктивністю оцінювання знань студентів та економізацією часу, який викладач використовує для перевірки робіт.

Модульний контроль передбачає написання контрольної роботи, яка має 10 варіантів, кожен із яких містить: 6 тестових питань із альтернативними відповідями, 2 відкритих питання, на які студенти повинні дати відповідь і одне завдання практичного характеру. Вирішення останнього, вимагає від майбутніх тренерів знання основних теоретичних положень та практичних методик, що застосовуються в фізичній реабілітації при різних захворюваннях, травмах та патологіях.

Підсумковий (семестровий) контроль - це екзамен, який студенти складають в усній формі за екзаменаційними білетами. Екзаменаційний білет має стандартну форму: три питання, зміст яких охоплює матеріал програми навчальної дисципліни.

Узагальнена оцінка складається з усіх балів, отриманих студентом під час поточного, модульного та підсумкового контролю, а також за виконання самостійної та практичних робіт.

Оцінка успішності студента $з$ дисципліни виставляється за 100-бальною та національною шкалами. Об'єктивне оцінювання навчальних досягнень студентів нами здійснюється за такими видами робіт і критеріями (табл.2).

Таблиця 2

Оцінювання успішності студентів

\begin{tabular}{|c|c|c|c|c|}
\hline $\mathrm{Nog}$ & Вид діяльності & $\begin{array}{l}\text { Кількість балів } \\
\text { за одиницю }\end{array}$ & $\begin{array}{l}\text { Кількість одиниць } \\
\text { до розрахунку }\end{array}$ & Всього \\
\hline 1. & Поточне тестування/опитування за темами & 4 & 8 & 32 \\
\hline 2. & Виконання практичної роботи & 1 & 8 & 8 \\
\hline 3. & Самостійна робота & 2 & 7 & 14 \\
\hline 4. & Модульна контрольна робота & 3 & 2 & 6 \\
\hline 5 & Екзамен & \multicolumn{3}{|c|}{40} \\
\hline & Всього & \multicolumn{3}{|c|}{100} \\
\hline
\end{tabular}

Кількість балів за роботу з теоретичним матеріалом, на практичних заняттях та під час виконання самостійної роботи залежить від дотримання таких вимог:

- своєчасність виконання навчальних завдань;

- повний обсяг виконання навчальних завдань;

- якість виконання навчальних завдань;

- $\quad$ самостійність виконання;

- $\quad$ творчий підхід у виконанні завдань;

- $\quad$ ініціатива у навчальній діяльності.

Одним із складників навчально-методичного комплексу викладання дисципліни $є$ пакет комплексних контрольних робіт (ККР), який є контрольним заходом, що здійснюється з метою виявлення рівня залишкових знань студентів та контролю за якістю навчального процесу. Пакет ККР містить 30 варіантів завдань, які охоплюють зміст усього курсу навчальної дисципліни. Кожен варіант контрольної роботи має чотири рівні: три з них спрямовані на перевірку теоретичних знань і один містить творче завдання для виявлення студентами практичних умінь і навичок.

Висновки та перспективи подальших досліджень. Таким чином, навчальна дисципліна «Фізична реабілітація» спрямована на поглиблення у майбутніх тренерів системи знань про ефективне і своєчасне застосування засобів відновлення стану здоров'я та функціональних можливостей організму, порушених в результаті захворювання; попередження передпатологічних та патологічних станів, що виникають при нераціональному застосуванні фізичних вправ; навчає застосовувати індивідуальні рекреаційно-оздоровчі режими рухової активності. Система підготовки висококваліфікованого фахівця передбачає аудиторну (лекції й практичні заняття) та самостійну роботу. 3 метою активізації науково-дослідної діяльності студентів на останній вид відводиться 2/3 усього навчального часу. 
Перспектива подальших досліджень полягає у вдосконаленні навчально-методичного комплексу дисципліни із впровадженням інноваційних педагогічних підходів до методичного забезпечення навчального процесу в умовах дистанційного навчання.

\section{Список використаних джерел}

Вовканич, А. С. (2013). Вступ до фізичної реабілітаціӥ: навч. посіб. Львів: ЛДУФК.

Лисенюк, В. П., Ткаліна, А. В. Реабілітаційна медицина: основні понятmя та дефініції. Взято 3 http://www.mifua.com/archive/article/34537

Мироненко, С. Г. (2017). Фізична реабілітаиія: [навч. програма]. Полтава: ПНПУ ім. В. Г. Короленка.

Отравенко, О. В. (2018). Моніторинг якості професійної підготовки майбутніх учителів фізичної культури в інноваційному освітньо-інформаційному просторі закладів вищої освіти. Вісник Кам'янець-Подільського нац. ун-ту. Фізичне виховання, спорт і здоров'я людини, 11, 282-291.

\section{References}

Lyseniuk, V. P., \& Tkalina, A. V. Reabilitatsiina medytsyna: osnovni poniattia ta definitsii [Rehabilitation medicine: basic concepts and definitions]. Retrieved from http://www.mif-ua.com/archive/article/34537 [in Ukrainian].

Myronenko, S. H. (2017). Fizychna reabilitatsiia [Physical rehabilitation]: [navch. prohrama]. Poltava: PNPU im. V. H. Korolenka [in Ukrainian].

Otravenko, O. V. (2018). Monitorynh yakosti profesiinoi pidhotovky maibutnikh uchyteliv fizychnoi kultury v innovatsiinomu osvitno-informatsiinomu prostori zakladiv vyshchoi osvity [Monitoring the quality of professional training of future physical education teachers in the innovative educational and information space of higher education institutions]. Visnyk KamianetsPodilskoho nats. un-tu. Fizychne vykhovannia, sport i zdorovia liudyny [Bulletin of Kamianets-Podilskyi National University un-tu. Physical education, sports and human health], 11, 282-291 [in Ukrainian].

Vovkanych, A. S. (2013). Vstup do fizychnoi reabilitatsii [Introduction to physical rehabilitation ]: navch. posib. Lviv: LDUFK [in Ukrainian].

MYRONENKO S., SHAPARENKO I.

Poltava V. G. Korolenko National Pedagogical University, Poltava, Ukraine

\section{THEORETICAL AND METHODOLOGICAL BASIS OF TEACHING THE DISCIPLINE "PHYSICAL REHABILITATION" IN THE PREPARATION OF BACHELORS IN THE SPECIALTY "PHYSICAL CULTURE AND SPORTS"}

The article reveals the theoretical and methodological foundations of teaching the compulsory discipline "Physical Rehabilitation" in the process of training trainers of educational qualification level "Bachelor" at the Faculty of Physical Education of Poltava National Pedagogical University named after V.G. Korolenko . The purpose, tasks of studying the discipline, the list of professional competencies and learning outcomes that students must have during the course are defined. A detailed description of the components of the educational and methodological complex of the discipline is given and presented. The components of educational-methodical complex of the subject was determined: training and content syllabus, supporting lecture notes with questions for self-instructional training, materials for practical classes and independent work, tests for current and module control of students knowledge, final tests. The system of training highly qualified specialists provides classroom (lectures and practical classes) and independent work. In order to promote research activities a master student has 2/3 from all kind of training time.

According to the educational subject syllabus the teacher suggested the following ways of evaluation of educational achievements of bachelor students as current, modular, final control. Current knowledge assessment and control module are performed in the forms of different tests. The final assessment consists of all points earned during the current testing and modul controls, as well as the performance of individual work. Overall evaluation of bachelor students success is rating and is set by 100 -scale system and totraditional scale accepted in Ukraine. A range of points that students may get for the topics of content moduleswere given.

Key words: educational and methodical complex, trainer, physical rehabilitation, medical physical culture, physical exercises.

Стаття надійшла до редакції 19.10.2020 p. 